\title{
Recurrent intramedullary epidermoid cyst of conus medullaris
}

\author{
Christina Fleming, Chandrasekaran Kaliaperumal, Michael O'Sullivan \\ Department of Neurosurgery, Cork University Hospital, Cork, Ireland \\ Correspondence to Mr Chandrasekaran Kaliaperumal, ckaliaperumal@gmail.com
}

\section{Summary}

Spinal intramedullary epidermoid cyst is a rare condition. Recurrent epidermoid cyst in the spine cord is known to occur. The authors describe a case of recurrent conus medullaris epidermoid cyst in a 24-year-old female. She initially presented at 7 years of age with bladder disturbance in the form of diurnal enuresis and recurrent urinary tract infection. MRI lumbar spine revealed a $4 \mathrm{~cm}$ conus medullaris epidermoid cyst. Since the initial presentation, the cyst had recurred seven times in the same location and she underwent surgical intervention in the form of exploration and debulking. This benign condition, owing to its anatomical location, has posed a surgical and overall management challenge. This occurrence is better managed in a tertiary-care centre requiring multi-disciplinary treatment approach.

\section{BACKGROUND}

Epidermoid cysts account for less than $1 \%$ of all intraspinal tumours. ${ }^{1}{ }^{2}$ Intracranial epidermoid cyst, though also rare, occurs more commonly with a ratio of cranial to spinal reported at $1: 14 .^{3}$ Spinal epidermoid cysts are usually intradural extramedullary while true intramedullary epidermoid cysts have only been reported in 60 cases so far in literature. We describe the first case of recurrent intramedullary conus medullaris epidermoid cyst in a young woman, which had recurred seven times in the same location, causing clinical deterioration and needing surgical intervention posing a challenge over the past two decades.

\section{CASE PRESENTATION}

\section{Initial presentation}

A 24-year-old initially presented at 7 years of age, with 2 -year history of recurrent urinary tract infections managed on oral antibiotics. One year later, she represented with progressive worsening of her symptoms and an MRI of lumbar spine revealed a $4 \mathrm{~cm}$ intramedullary lesion in the conus medullaris opposite vertebrae L1 and L2. She was referred to neurosurgical service for surgical management. She had an insidious onset of subtle neurological symptoms and unsteady gait also over the preceding few months and examination at the time revealed left-sided signs of increased lower limb tone, brisk patellar reflex, upgoing plantar in association with perianal hypoaesthesia for light touch and pinprick with normal power. Lumbar laminectomy (L1-3) was performed along with exenteration of the dermoid cyst. Postoperatively she was left with loss of bladder sphincter control, left-sided foot drop, bilateral thigh and buttock anaesthesia and lower limb weakness for the past 14 years. She was intermittently self-catheterising since then and physiotherapy led to good clinical recovery. She was able to mobilse with the help of a walking stick.

\section{Recurrence}

Five years later, after experiencing 9 months of progressive lower back pain radiating to her left hip, she

Table 1 Summary of the treatment offered to the patient with indications and outcome

\begin{tabular}{|c|c|c|c|c|}
\hline No. & Year & Surgical procedure & Indication & Outcome \\
\hline 1 & 1990 & $\begin{array}{l}\text { L1-3 laminectomy with exenteration of cyst in the } \\
\text { conus medullaris }\end{array}$ & Recurrent UTI and bladder disturbance (enuresis) & $\begin{array}{l}\text { 1. Loss of bladder sphincter control } \\
\text { 2. Left-sided foot drop } \\
\text { 3. Bilateral thigh and buttock anaesthesia } \\
\text { 4. Bilateral lower limb weakness }\end{array}$ \\
\hline 2 & 1995 & $\begin{array}{l}\text { Re-exploration of conus medullaris with radical } \\
\text { evacuation of cyst }\end{array}$ & Lower back pain radiating to left hip & Pain free for 4.5 years \\
\hline 3 & 2000 & $\begin{array}{l}\text { Reopening of previous surgical incision and further } \\
\text { evacuation of cyst }\end{array}$ & Lower back pain & Nil new \\
\hline 4 & 2004 & $\begin{array}{l}\text { Re-exploration of lumbar wound and complete } \\
\text { debulking of intramedullary cyst (pseudomeningocoele } \\
\text { formation to allow herniation of cyst contents) }\end{array}$ & Persistent left hip and groin pain & $\begin{array}{l}\text { Chemical meningitis and increasing } \\
\text { back pain }\end{array}$ \\
\hline 5 & 2004 & $\begin{array}{l}\text { Decompression revision with reopening and } \\
\text { evacuation of contents } 3 \text { weeks post op }\end{array}$ & Increasing lower back pain with urinary retention & Persistence of pain but less severe \\
\hline 6 & 2009 & Reopening of wound, further evacuation of cyst & $\begin{array}{l}\text { Worsening pain and sensory disturbance affecting } \\
\text { right leg also }\end{array}$ & $\begin{array}{l}\text { 1. Pain resolved } \\
\text { 2. Persistent neuropathic pain in both } \\
\text { legs } \\
\text { 3. Weakness left knee extension }\end{array}$ \\
\hline 7 & 2011 & $\begin{array}{l}\text { L1/L2 re-exploration and debulking of intramedullary } \\
\text { epidermoid cyst }\end{array}$ & $\begin{array}{l}\text { Increasing dysmobility due to back pain, lower limb } \\
\text { weakness and dysaesthesia leading to poor balance }\end{array}$ & $\begin{array}{l}\text { Lower back pain still present post op but } \\
\text { less severe }\end{array}$ \\
\hline
\end{tabular}

UTI, urinary tract infection. 
underwent an MRI, which showed a cyst recurrence with an increase in the size to $5 \mathrm{~cm}$. Subsequently, a re-exploration of conus medullaris was performed with radical evacuation of the cyst. Surgical intervention led to good

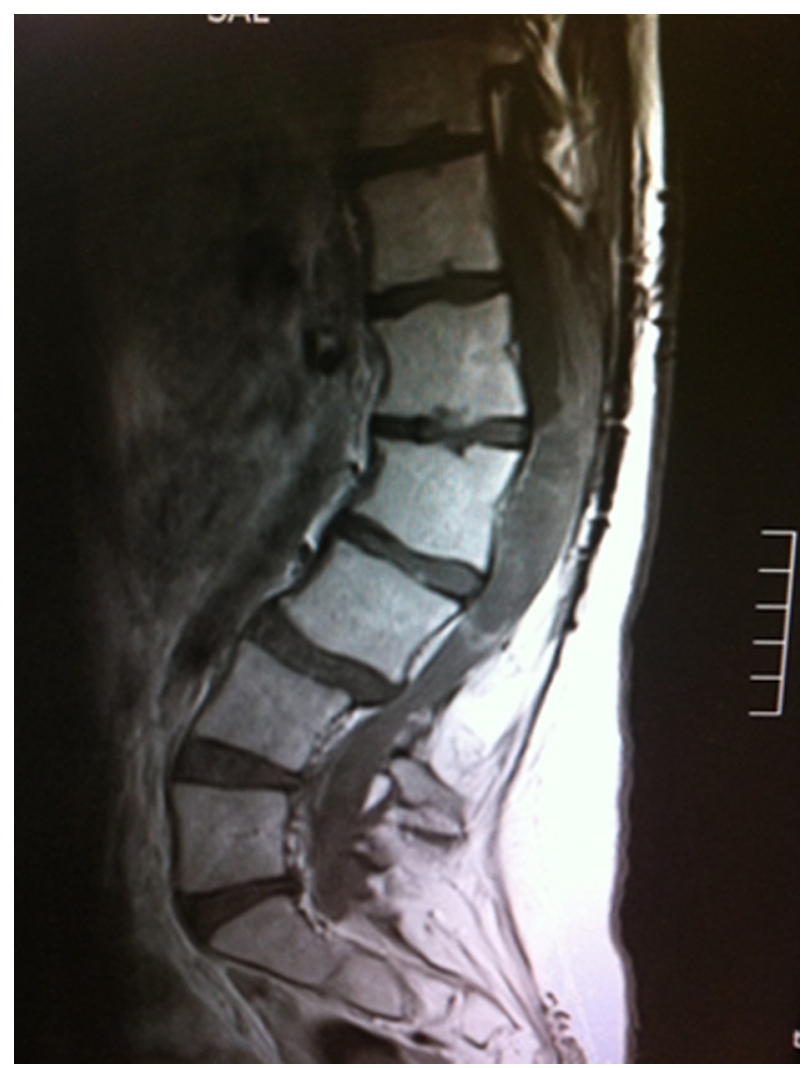

Figure 1 Sagittal MRI T1 weighted imaging of the lumbar spine demonstrating the isointense signal to cerebrospinal fluid. symptomatic pain relief with an unaltered neurological condition in her lower limbs. Five years after a pain free interval she required four further re-explorations to manage continued pain and mobility problems for recurrence of epidermoid cyst. Table 1 summarises the procedures performed since initial presentation with the indications and outcomes at every stage. She had an unevent postoperative period except in one occasion when a novel approach was attempted when she presented for the fourth time. At that stage, re-exploration of the lumbar wound and debulking of the cyst was performed. A small inferior hiatus was left behind to form a pseudomeningocele to allow herniation of the cyst contents, in an attempt to decompress the cyst contents. Three weeks postoperatively, she developed chemical meningitis and her back pain had deteriorated.

As surgical option was technically challenging, she was managed by the pain management team. Her neurological symptoms however, continued to progress and again 5 years later, with increasing back pain and left hip pain associated with sensory disturbance and fasciculations above right knee and in right buttock with weakness of the right foot. Re-exploration and further evacuation of the cyst was performed. While this allowed reduction of her back pain initially, she subsequently developed neuropathic pain in both legs and weakness in left knee extension possibly from L3 motor nerve root damage. Gabapentin was commenced and this led to gradual improvement in her back and leg pain with a reasonable quality of life.

\section{Current presentation}

Recently prior to this presentation, she experienced a marked deterioration in her symptoms due to poor balance leading to recurrent falls and difficulty in walking. She

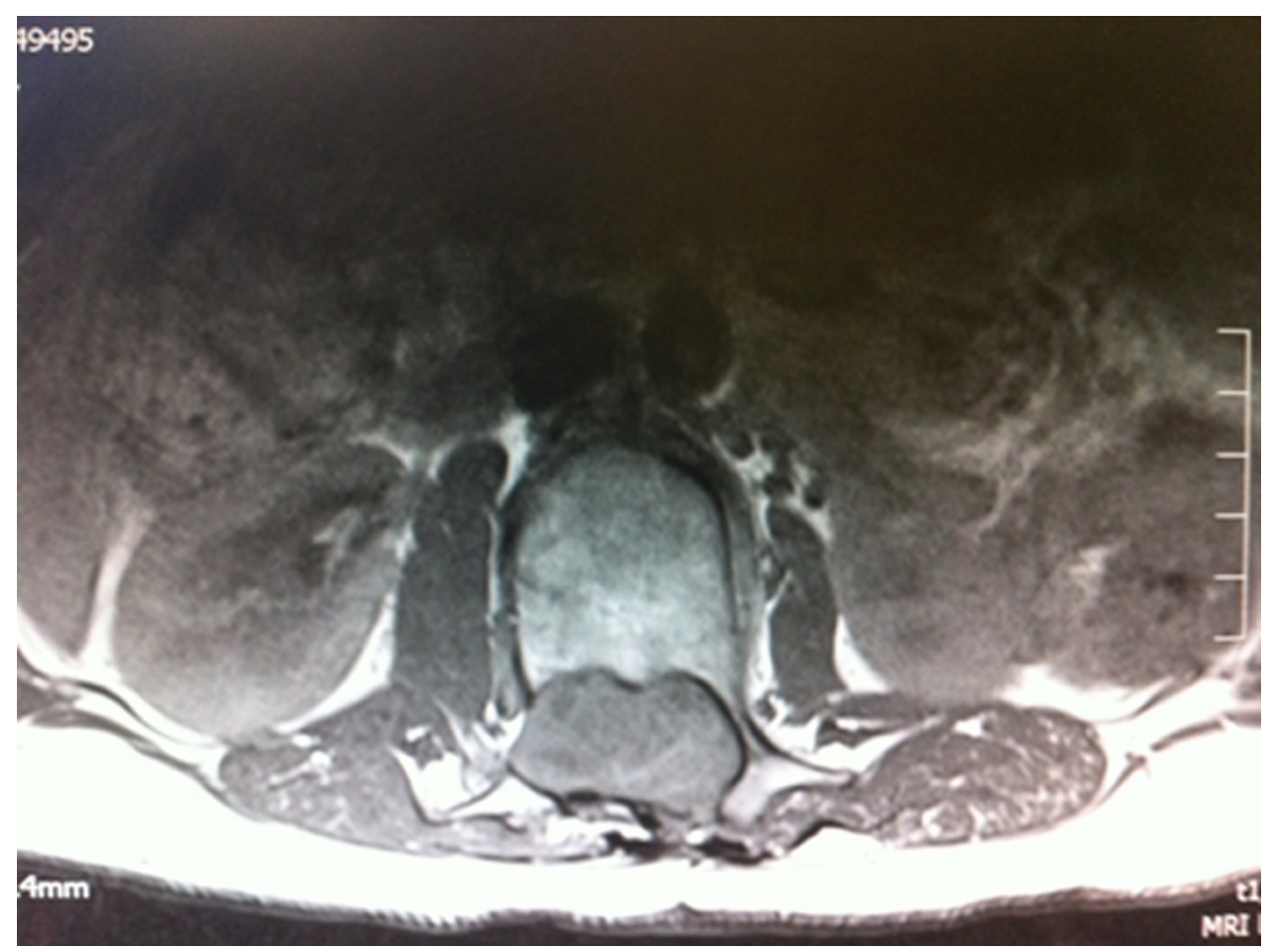

Figure 2 Axial T1 weighted MRI demonstrating the lesion. 
had recurrence of debilitating lower back pain radiating to her right leg. Further MRI imaging of her lumbar spine revealed recurrent epidermoid cyst in the conus medullaris (figures 1 and 2).

\section{INVESTIGATIONS}

Further MRI imaging of her lumbar spine revealed recurrent epidermoid cyst in the conus medullaris. Epidermoid

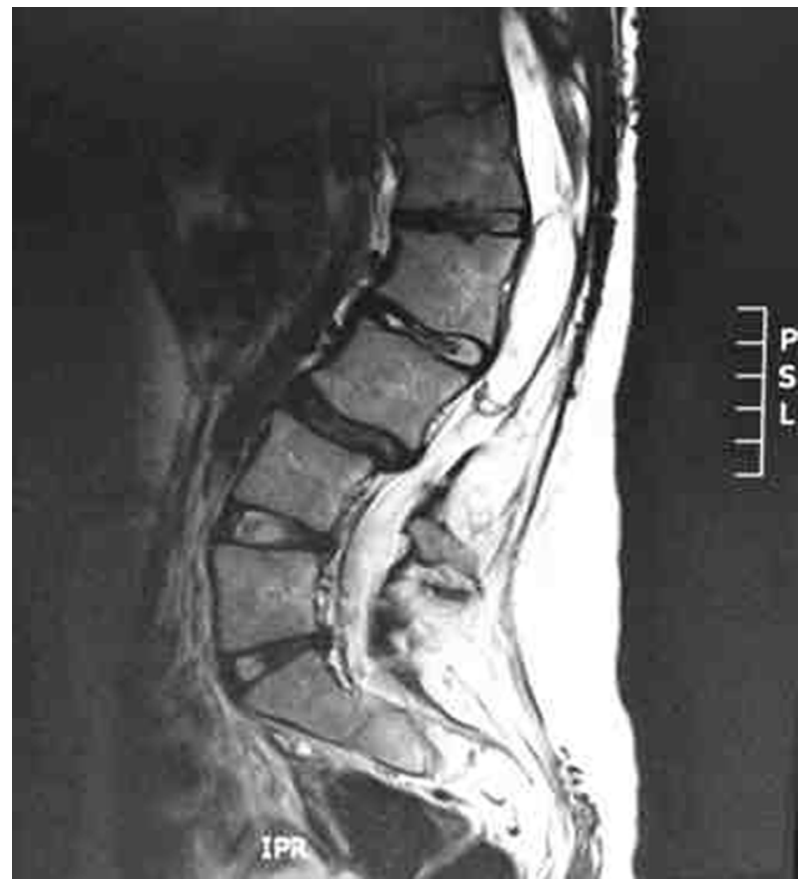

Figure 3 Sagittal T2 weighted MRI demonstrating high signal in the conus medullaris and previous laminectomy defect and scar tissue. cyst have a classic isointense appearance on T1weighted MRI and it was well defined $5 \mathrm{~cm}$ cranio-caudally by 3 $\mathrm{cm}$ antero-posteriorly in dimensions (figures 1 and 2). T2 weighted MRI sequence showed high signal intensity (figures 3 and 4). In a previously undiagnosed epidermoid cyst, MRI and CT imaging may not be diagnostic and fluid attenuated inversion recovery (FLAIR) and diffusion weighted imaging (DWI) sequence may be required. ${ }^{1}$

\section{DIFFERENTIAL DIAGNOSIS}

- Arachnoid cyst-MRI follows cerebrospinal fluid signal intensity on all the sequences (T1, T2, DWI and FLAIR)

- Neurentric cyst-these are intradural cyst usually noted ventral to the cord but may be noted dorsally and intramedullary. This may be associated with vertebral anomalies and are hyperintense on MRI. Definite diagnosis is by histopathology.

\section{TREATMENT}

She underwent a L1/L2 re-exploration and debulking of the epidermoid cyst. Due to previous laminectomy, there was a dense band of scar tissue extending all the way to the conus medullaris from subcutaneous tissue. Microscopic debulking was performed and the cyst capsule adherent to the conus was left alone with a view to preserve the neurological function. The cyst had a classic white pearly appearance and was debulked using Cavitron Ultrasonic aspirator. ${ }^{4}$ Histopathological examination showed desquamated epithelial keratin and a positive staining with antibodies to epithelial membrane antigen and cytokeratin suggestive of epidermoid cyst. This procedure led to mild improvement in her back pain.

The table 1 below summarises the treatment offered to the patient with indications and outcome.

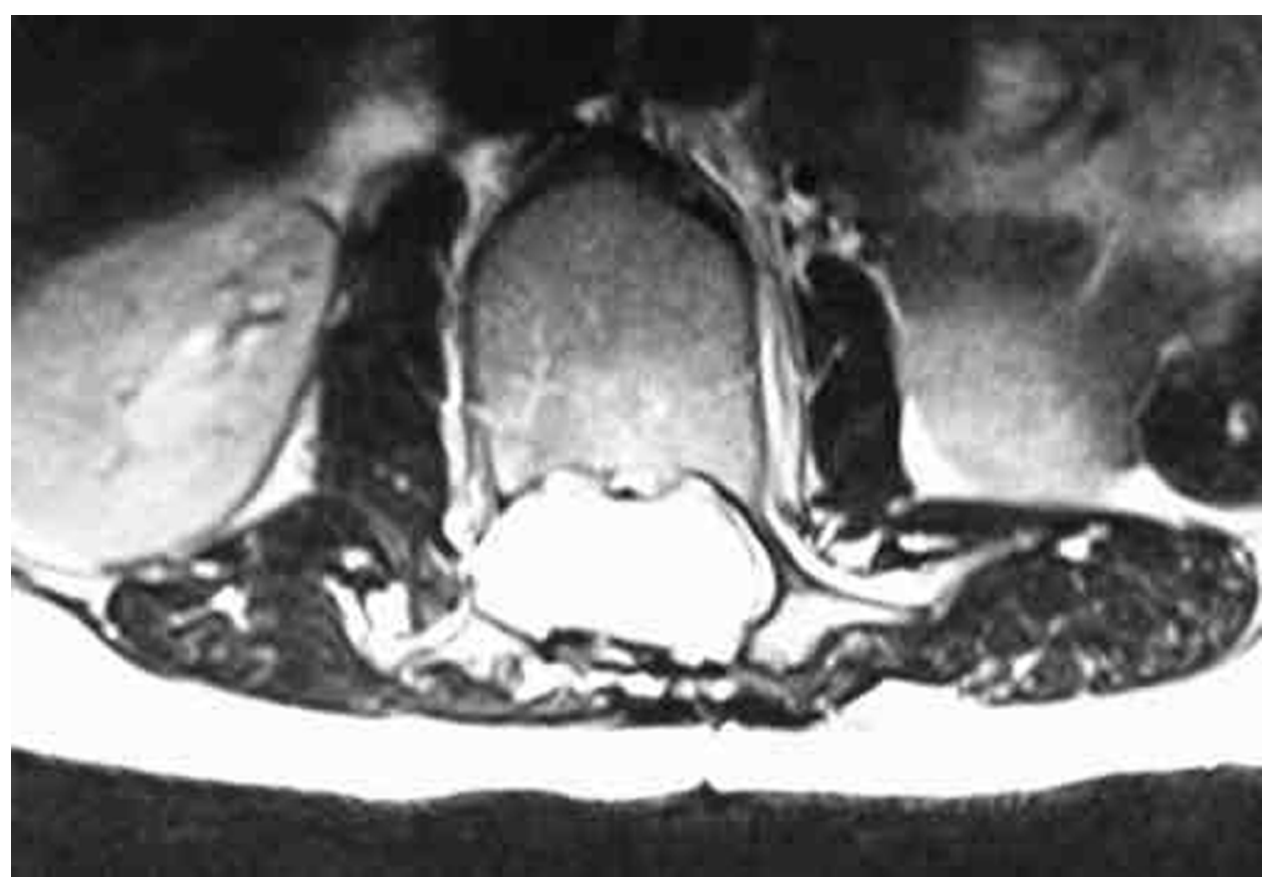

Figure 4 Axial T2 weighted MRI demonstrating the cyst occupying the whole of conus medullaris/spinal canal. 


\section{OUTCOME AND FOLLOW-UP}

The patient is currently left with bilateral lower limb weakness (3/5 in her left and 4/5 in her right leg) and required bilateral ankle braces and walking sticks to facilitate mobility. She is on multimodal pain relief and was discharged home after input from a multi-disciplinary team.

\section{DISCUSSION}

Surgical intervention in the form of excision with capsule remains the main modality of treatment for spinal epidermoid cyst. In a previously undiagnosed epidermoid cyst, MRI and CT imaging may not be diagnostic and FLAIR and DWI MRI sequence may be required. In the absence of these special sequences in imaging this condition can be misdiagnosed as arachnoid cyst. Epidermoid spinal cysts are notoriously difficult to treat surgically as it may be difficult to excise the cyst capsule completely, allowing a high risk of recurrence. Being a benign condition, due to its anatomical location, it had posed a surgical challenge so far and complete excision was never achieved. This case also clearly highlights possibility of the array of neurological deficits that can occur secondary to surgical intervention from managing this condition and inability to produce a definitive cure or long term benefit. Recurrence of epidermoid spinal cysts to this degree has not been previously described to our knowledge. However, a case in 1977 described a 17-year-old girl who required three surgical interventions for decompression of a recurrent cyst of this type intracranially. An Ommaya reservoir was inserted into the cyst to allow for future drainage. This techinque is fraught with a risk of infection up to $6 \%$.

It is impossible to fully appreciate impact of this recurrence without considering the effect it has on other aspects of the patient's life causing physical and psychological distress. As she approaches this stage in her life, she also has concerns regarding future pregnancy, related to how her body would cope with such a significant stress and pain management options during pregnancy, as many such agents are associated with possible impact on the fetus.

To conclude, recurrent epidermoid cyst of conus medullaris is rare and it may pose a management challenge. Complete excision of the epidermoid cyst remains the standard treatment modality, however, in our case complete excision was not possible due to its anatomical location. This has produced a significant impact on the patient physical and psychological well being. We recommend that this condition be better managed in a tertiarycare setting. Treatment by a multi-disciplinary approach with input from specialities comprising of neurosurgery, urology, pain physician, physiotherapy, occupational therapy, psychology and psychiatry, is a key feature in the management. Our patient will be followed up with an MRI scan of lumbar spine when she experiences any change in her neurological status in the future.

\section{Learning points}

- Management of conus medullaris epidermiod cyst may pose a technical challenge and recurrence should be anticipated.

- We recommend that this condition be better managed in a tertiary-care setting.

- Treatment by a multi-disciplinary approach, with input from specialities comprising of neurosurgery, urology, pain physician, physiotherapy, occupational therapy, psychology and psychiatry, is a key feature in the management.

- FLAIR and DWI MRI sequence is essential to differentiate this condition from spinal arachnoid cyst.

- Follow-up with an MRI scan of lumbar spine is recommended only if there any change in clinical symptoms.

\section{Competing interests None.}

Patient consent Obtained.

\section{REFERENCES}

1. Amato VG, Assietti R, Arienta C. Intramedullary epidermoid cyst: preoperative diagnosis and surgical management after MRI introduction. Case report and updating of the literature. J Neurosurg Sci 2002; 46:122-6.

2. Roux A, Mercier C, Larbrisseau A, et al. Intramedullary epidermoid cysts of the spinal cord. Case report. J Neurosurg 1992;76:528-33.

3. Alves A, Norrell H. Intramedullary epidermoid tumours of the spinal cord. Report of a case and review of the literature. Int Surg 1975;4:239-43.

4. Epstein F. The Cavitron ultrasonic aspirator in tumor surgery. Clin Neurosurg 1983;31:497-505.

This pdf has been created automatically from the final edited text and images.

Copyright 2011 BMJ Publishing Group. All rights reserved. For permission to reuse any of this content visit http://group.bmj.com/group/rights-licensing/permissions.

BMJ Case Report Fellows may re-use this article for personal use and teaching without any further permission.

Please cite this article as follows (you will need to access the article online to obtain the date of publication).

Fleming C, Kaliaperumal C, O'Sullivan M. Recurrent intramedullary epidermoid cyst of conus medullaris. BMJ Case Reports 2011; 10.1136/bcr.11.2011.5090, Published XXX

Become a Fellow of BMJ Case Reports today and you can:

- Submit as many cases as you like

- Enjoy fast sympathetic peer review and rapid publication of accepted articles

- Access all the published articles

- Re-use any of the published material for personal use and teaching without further permission

For information on Institutional Fellowships contact consortiasales@bmjgroup.com

Visit casereports.bmj.com for more articles like this and to become a Fellow 